\title{
ENTRE A ACEITAÇÃO E A FUGA: \\ a juventude negra em trânsito nos currículos escolares
}

\author{
Eliana Póvoas Pereira Estrela Brito'
}

\section{RESUMO}

Este artigo beneficia-se de fragmentos extraídos de pesquisas realizadas em uma escola do ensino médio da rede pública do Estado da Bahia. As questões que orientam este estudo residem em acompanhar os movimentos direcionados à subversão dos dogmas, das normatizações e dos mecanismos de controle colocados em funcionamento pelos e nos processos de escolarização. Pergunta-se: é possível escapar das armadilhas das identidades fixadas pelas normativas institucionais? É possível desestabilizar os caprichos da disciplina e seus efeitos sobre os corpos negros? Ao interrogar essas práticas curriculares na perspectiva da diferença, ou ainda, ao perguntar, parafraseando Stuart Hall (2002), "que 'negro' é esse na cultura negra?", o estudo apontou para movimentos de capturas e resistências aos lugares institucionais (pré)vistos pelos planejamentos curriculares.

Palavras-chave: Currículo. Diferença. Relações étnico-raciais.

\section{BETWEEN ACCEPTANCE AND ESCAPE:}

\section{black youth in transit in school curriculum}

\begin{abstract}
This article benefits from fragments extracted from research carried out at a secondary education public school in the State of Bahia. The Questions that guide this study reside in accompanying the movements directed to subversion of dogmas, standardization and control mechanisms put into operation by and in the processes of schooling. Question: Is it possible to escape the traps of identities fixed by institutional norms? Is it possible to destabilize the whims of discipline and its effects on black bodies? When interrogating these curricular practices in the perspective of the difference, or, when asking, paraphrasing Stuart Hall (1992), "What is This "Black" in Black Popular Culture?', the study pointed to movements of catches and resistances to the institutional places (pre)established by curricular planning.
\end{abstract}

Keywords: Curriculum. Difference. Ethnic-racial relations.

\footnotetext{
1 Doutora em Educação (UFRGS). Professora do Programa de Pós-Graduação em Ensino e Relações Étnico-Raciais (PPGER) e do Programa de Pós-Graduação Estado e Sociedade (PPGES) da Universidade Federal do Sul da Bahia (UFSB). Porto Seguro, Bahia, Brasil. Orcid iD: http://orcid.org/0000-0002-4563-1354. E-mail: elianapovoas.ppger@gmail.com e epovoas@ufsb.edu.br
} 


\section{ENTRE LA ACEPTACIÓN Y LA FUGA:}

\section{la juventud negra en tránsito en los currículum escolares}

\section{RESUMEN}

Este artículo se beneficia de fragmentos extraídos de investigaciones realizadas en una escuela de enseñanza media de la red pública del Estado de Bahía. Las cuestiones que orientan este estudio residen en acompañar los movimientos dirigidos a la subversión de los dogmas, de las normatizaciones y de los mecanismos de control puestos en funcionamiento por los y en los procesos de escolarización. Nos preguntamos: $\dot{\imath}$ Es posible escapar de las trampas de las identidades fijadas por las normativas institucionales? ¿ Es posible desestabilizar los caprichos de la disciplina y sus efectos sobre los cuerpos negros? Al interrogar estas prácticas curriculares en la perspectiva de la diferencia, o aún, al preguntársele, parafraseando a Stuart Hall (2002), "zqué negro es éste en la cultura negra?", El estudio apuntó a los movimientos de capturas y resistencias, a los lugares institucionales (pre) visados por las planificaciones curriculares.

Palabras clave: Currículo. Diferencia. Relaciones étnico-raciales.

\section{INTRODUÇÃO}

... vou começar the contando uma história... Estava eu, esperando minha amiga na porta do banheiro, quando um menino branco e hétero falava de racismo reverso na escola... Dizia alto e em bom tom, que do jeito que as coisas andavam não podia continuar, pois os negros estavam oprimindo os brancos. Na hora não aguentei e comecei a debater com ele, perdi totalmente a compostura, pois, de imediato percebi que ele falava pra que eu, mulher negra, ouvisse. Têm pessoas aqui que não dá nem para explicar como são racistas ${ }^{2}$.

Aqui, na escola, mas, também na sociedade em geral, se você não segue um padrão é visto como estranho, como diz a letra de uma música que eu gosto, "é melhor ser odiado, do que ser amado por uma coisa que você não é". As pessoas querem ser amadas e isso é muito triste, porque elas se agridem, e o mais triste é que se adaptam para serem aceitas da forma como a escola e a sociedade querem. Mas, eu não entro nesta vibe, não 3 .

Trago como epígrafe da apresentação/introdução deste artigo, relatos de estudantes registrados por ocasião de uma roda de conversa em que discutimos o racismo e as práticas racistas na escola. Depoimentos esses

\footnotetext{
2 Relato de uma estudante negra, 18 anos, estudante do 2 . ano do ensino médio da escola investigada.

3 Depoimento de um estudante negro e gay, aluno do 1. ano do ensino médio da escola estudada.
} 
que se constituíram em fluxo de forças que permitiram a emergência de novas problemáticas ao indicarem que as questões anteriormente definidas dão-se com outras formas e forças nos cotidianos escolares. Logo, pensar as relações Étnico-Raciais deslocadas das disciplinas científicas que compõem o currículo, na acepção da seleção, hierarquização e distribuição dos conhecimentos, foi um desafio mobilizador deste estudo.

Tendo como foco o "ensino" das relações raciais que, por força da Lei 10.639/2003 e da Lei 11.645/2008, inclui no currículo oficial da rede de ensino a obrigatoriedade da temática "História e cultura afro-brasileira e indígena", a pesquisa que moveu este trabalho, no lugar de perguntar se a escola incluía esses saberes nos currículos ${ }^{4}$, passou a questionar: é possível escapar das armadilhas das identidades fixadas pelas normativas institucionais? É possível desestabilizar os caprichos das relações de poder e seus efeitos sobre os corpos negros?

"Mas a escola não tem que ensinar?", interroga a professora Elizabeth Macedo (2017), em um artigo que tem essa pergunta como título e no qual a teoria curricular é analisada como discurso normatizador que delimita o que pode ser entendido como currículo e, de certa forma, como educação e escola. A autora argumenta que a racionalidade que preside a teoria curricular potencializa que o sujeito se reconheça na cultura trazendo, como consequência, efeitos perversos para a diferença. "O reconhecimento sutura a vulnerabilidade constitutiva da subjetividade e conforma os sujeitos ao que Butler chama de esquema de intelegibilidade ultrajante" (MACEDO, 2017, p. 539). Decorre desse entendimento sua defesa a favor de uma educação alicerçada pela vulnerabilidade como forma de dar "visibilidade à experiência de estar com o outro." (ib).

\footnotetext{
4 Inicialmente, a pesquisa trabalhava com a hipótese de que um currículo inclusivo dos saberes e culturas afro e afro-brasileiras potencializaria condições para que os/as estudantes se reconhecessem na (sua) cultura e, por efeito, a escola estaria cumprindo sua função formativa. Essa assertiva, se confirmada, colocaria em xeque um conjunto de argumentos, frequentemente, encontrados na literatura que trabalha com a educação étnico-racial, quando afirma que, apesar de existência de leis voltadas ao antirracismo na educação, as escolas não cumprem.
} 
A crença na razão universal e seus efeitos sobre as práticas curriculares: planejar com o intuito de prever o percurso; predizer o que e como devem ser ensinados os conhecimentos; antever os modos pelos quais o sujeito epistêmico descobrirá os conhecimentos válidos e verdadeiros, respalda-se em "uma concepção do conhecimento como representação ('verdadeira'), como correspondência ou adequação a alguma suposta e preexistente realidade, a alguma presumida coisa-em-si" (CORAZZA, S; TADEU, T. 2003, p. 37).

A constatação de que a teorização curricular, presidida pelos princípios da filosofia da representação e sua insistência na crença do sujeito da razão, da verdade, da unidade, levou Macedo (2017, p.541) a defender o argumento de que a escola não tem que ensinar. "Ela tem que educar e isso não é ensinar". Educar na perspectiva da "despossessãovulnerabilidade" subverte a lógica curricular do reconhecimento a partir do já dado. Talvez, por isso mesmo, as políticas curriculares tentem afastar os perigos de sua materialidade nos processos de escolarização (MACEDO, 2017).

O esforço em analisar o currículo nas frestas dos pressupostos conceituais da filosofia da representação, a partir de um "pensamento sem imagem" (DELEUZE, 1988), tem levado alguns/algumas estudiosos/as 5 a problematizarem o currículo a partir da filosofia da diferença, em detrimento da ideia de identidade que "[...] é sempre em relação a uma identidade concebida, a uma analogia julgada, a uma oposição imaginada, a uma similitude percebida que a diferença se torna objeto de representação" (DELEUZE, 1988, p.136). São estudos-convites que abrem possibilidades para problematizações curriculares que ultrapassem as nossas velhas constatações críticas, decorrentes dos processos de plastificação curricular, para descobrir em suas rachaduras a emergência de híbridos, multiplicidades, singularidades.

\footnotetext{
${ }^{5}$ Ver: MACEDO (2006; 2017); PARAISO (2012; 2015; 2016); GALLO (2003;2007), dentre outros.
} 
Para tanto, acompanhamos o cotidiano de uma escola pública de Porto Seguro - Bahia, por um período de dois anos letivos (2017 e 2018). Nesse percurso, observamos de forma participativa as movimentações da escola em diferentes tempos e espaços. Conversamos com professoras e professores, servidores e servidoras dos setores de apoio (merendeira, faxineira, guarda, porteiros), setores administrativos (gestores/as, secretários/as, coordenadores/as de área e coordenação pedagógica) e realizamos entrevistas e rodas de conversas com as/os estudantes. Participamos, também, das chamadas "Jornadas Pedagógicas6" (2017; 2018 e 2019) e de algumas das reuniões de Atividades Complementares (ACs). Mantive com estudantes e docentes muitas conversas informais nos intervalos das aulas, recreios, fugidas das aulas, filas de espera por transporte escolar, dentre outros.

Busquei diagramar os movimentos que ocorriam nas fissuras criadas frente à imposição de um currículo, fortemente orientado pelos pressupostos da identidade e da unidade, e a desobediência a eles. No limite, meu interesse residia em compreender os movimentos que ocorrem entre a diferença e tudo aquilo que é produzido por um currículo que objetiva o reconhecimento do sujeito e do conhecimento, a partir de suas predefinições.

Por óbvio, não se trata aqui de um exercício que supõe estabelecer a oposição da identidade à diferença como se o espaço das relações escolares operasse de forma dicotômica. Antes, trata-se de compreender as relações de força emergentes no espaço micropolítico da escola. Nas palavras de Gallo (2002, p.173): "Se a educação maior é produzida na macropolítica, nos gabinetes, expressa nos documentos, a educação menor está no âmbito da micropolítica, na sala de aula, expressa nas ações cotidianas de cada um". A noção de "educação menor", proposta por Gallo, permite-nos pensar que, dentro da maquinaria escolar normatizada e

\footnotetext{
${ }^{6}$ As Jornadas Pedagógicas são uma iniciativa da Secretaria Estadual de Educação da Bahia, com o objetivo de reunir os/as professores/as para a realização do planejamento do ano letivo. Embora, os temas e a metodologia de trabalho sejam comuns a todas as escolas da rede estadual de ensino baiana, cabe à cada escola organizar as atividades locais.
} 
disciplinada pelo Estado, operam máquinas de guerra que produzem singularidades. Ou seja,

De dentro de a máquina opor resistência, quebrar os mecanismos, como ludistas pós-modernos, botando fogo na máquina de controle, criando novas possibilidades. A educação menor age exatamente nessas brechas para, a partir do deserto e da miséria da sala de aula, fazer emergir possibilidades que escapem a qualquer controle (GALLO, 2002, p. 175).

Para tanto, o presente artigo encontra-se assim estruturado: no primeiro tópico, discute a escola enquanto uma instituição social criada na modernidade e discute os princípios utilizados para sua institucionalização. Na sequência, problematiza as dificuldades que a escola vem enfrentando na contemporaneidade frente às mudanças sociais que caracterizam as sociedades atuais. No tópico: Currículo: capturas e fugas são analisadas, a partir de situações extraídas da pesquisa realizada, movimentos curriculares que se desenham no cotidiano da realidade escolar estudada. Para fechar o texto, o artigo retoma as questões apresentadas com o intuito de abrir a discussão e contribuir para que novas pesquisas na área possam ser realizadas.

\section{SOBRE ESCOLA E SAPUCAIAS7}

Professora, não fique aí não... essa árvore vai cair, olha como os galhos estão tortos ... basta um ventinho e fuw... cais!

Esta observação foi-me dirigida por um estudante, numa espécie de alerta aos prováveis perigos em sentar em um pequeno banco, abaixo de uma sapucaieira, que se localizava no centro do pátio da escola. Meu estranhamento frente a essa chamada de atenção deu-se em função de que, ao longe, ela mostrava-se exuberante e exibia, sem cerimônias, flores

\footnotetext{
7 Sapucaia é o nome de uma árvore nativa, exclusiva do Brasil, e muito cultivada no sul da Bahia, por exercer a função de proteção, a partir de suas largas copas, do cultivo do cacau.

8 Observação feita por um estudante enquanto forma de chamar a atenção aos supostos "perigos" das rachaduras da árvore.
} 
que coloriam a escola. É verdade que, ao observá-la mais de perto, foi possível identificar que havia vários galhos quebrados, flores e sementes caídas espalhavam-se pelo chão, mas, no geral, sua estrutura continuava firme e aparentava robustez. De fato, apesar dos abalos sofridos, a sapucaia parecia insistir em dar visibilidade à força de sua imagem-conhecimento e de seus enraizamentos nas formas pelas quais a escola pensa, planeja, organiza e põe em circulação suas práticas escolares.

Será a escola uma sapucaia? Ou seria a sapucaia a própria escola? Julia Varela e Fernando Alvarez-Uria (1996), ao fazerem uma genealogia da escola moderna, mostram-nos com clareza, como se deu a passagem de uma educação escolástica, característica da época medieval, para o surgimento da escola moderna, ou nas palavras dos autores, da "maquinaria escolar". Assim, na realidade "[...] esta maquinaria de governo da infância não apareceu de súbito, mas, ao invés disso, reuniu e instrumentalizou uma série de dispositivos que emergiram e se configuraram a partir do século XVI" (ib. p.1). É importante que tenhamos clareza que, embora os processos de escolarização sejam relativamente novos, remetendo-se ao século XIX, os princípios que materializaram a institucionalização da escola moderna datam do século XVI. Nas palavras de Paoli (2014, s/p.), "Deus vai dando lugar à razão como princípio explicativo e orientador da vida social, onde se inventarão novas tecnologias de controle, disciplinamento, orientação e instrumentalização específicas para a configuração de uma nova sociedade".

Recorrendo, uma vez mais, à genealogia realizada por Varela e Alvarez-Uria (1996), dentre o conjunto de dimensões que, ao se amalgamar em princípios da época, permitiram o surgimento da escola moderna, encontram-se: a definição de um estatuto da infância; a emergência de um espaço específico destinado à educação das crianças; o aparecimento de um corpo de especialistas da infância, dotados de tecnologias específicas e de "elaborados" códigos teóricos; a destruição de outros modos de educação e a institucionalização propriamente dita da escola: a imposição 
da obrigatoriedade escolar decretada pelos poderes públicos e sancionada pelas leis (Cf. Varela e Alvarez-Uria, 1996).

Percebe-se, portanto, que a invenção da escola e sua obrigatoriedade para todas as crianças e, posteriormente, para os jovens, não acontece de forma neutra e distanciada das demandas sociais e políticas exigidas pelo novo regime econômico, político e social que se instaurava. A formação dos sujeitos "iluminados" e conhecedores das especificidades dos saberes presentes nas ramificações da grande árvore do saber, proposta por Descartes, correlacionam-se e possibilita as condições para que as crianças e jovens das classes trabalhadoras sejam "ensinadas" no melhor estilo da burguesia.

Não se trata, no entanto, de pensar que a escola simplesmente reproduza os valores $e$ as diferenças sociais presentes na sociedade capitalista, na tentativa de manter seu status quo, conforme Althusser e outros estudiosos das chamadas teorias da reprodução defendiam. Antes, trata-se de uma nova tecnologia de poder que fez operar uma série de dispositivos de controle nas instituições de sequestro (prisão, quartel, hospício, hospital...) e "[...] fez funcionar o espaço escolar como uma máquina de ensinar, mas também de vigiar, de hierarquizar, de recompensar" (FOUCAULT, 1994, p.134).

Emerge neste cenário a figura do professor duplamente empoderada: adquire o estatuto de funcionário público e conhecedor dos saberes das ciências pedagógicas e seus matizes com o campo da psicologia interferindo na educação e, ao mesmo tempo, fortalecendo seus princípios educativos ao Ihe conferir uma "dupla cientificidade" (Varela e Alvarez-Uria, 1996, p. 14). O professor, dotado dos saberes/poderes das ciências, passa a interferir na regulação das condutas, sejam elas de si (auto- regulação) ou das relações estabelecidas na sociedade. Em poucas palavras, pela disciplinarização e governo dos corpos infantis e juvenis, a escola surge e consolida-se na modernidade como uma maquinaria que, a um só tempo, produziu saberes e práticas sobre a infância e a juventude. 
Nesse sentido, a escola moderna tornou-se um lugar de excelência para o exercício do poder disciplinar, ao organizar e colocar em funcionamento uma nova racionalidade política para os tempos/espaços de aprendizagens. Determinando seriações, regrando o tempo/espaço de aprender, o tempo/espaço de brincar, o tempo/espaço em que cada estudante deveria ocupar-se individualmente com suas aprendizagens, colocou em circulação uma nova economia do poder, tornando possível o controle das atividades realizadas individualmente por cada estudante e o trabalho simultâneo de todos. Assim, a escola moderna cumpre com os objetivos das disciplinas na fabricação de corpos dóceis e uteis ao novo regime social, político e econômico instaurado.

Não se pode deixar de considerar que, simultaneamente aos exercícios do poder disciplinar, a escola moderna foi consolidando-se como instituição formativa, mantendo consigo os ideais do iluminismo e do racionalismo iniciado pela conhecida Revolução Científica do século XVI. Esse ideário traz fortes modificações no modo de existência das formações discursivas constitutivas da época que a precede, pois passa a atribuir à razão (e não mais à fé) a condição da verdade. Com a primazia da razão como forma única e verdadeira de conhecer e interferir no mundo dá-se início a uma rápida proliferação das disciplinas e, com elas, as ramificações por áreas específicas do saber.

Foi a partir dessa configuração que Descartes criou a imagem da árvore dos saberes como representação da estrutura e organização dos conhecimentos científicos. Nas palavras de Gallo (2007, p, 3):

Nessa imagem, as raízes da árvore representariam o mito, como conhecimento originário; o tronco representaria a filosofia, que dá consistência e sustentação para o todo; os galhos, por sua vez, representariam as diferentes disciplinas científicas, que por sua vez se subdividem em inúmeros ramos.

Gallo (2007) afirma que é "[...] quase impossível não transportar imediatamente a imagem da árvore para o currículo disciplinar" e, de fato, é uma metáfora que identifica muito bem as formas pelas quais os currículos 
escolares, em sua grande maioria, são pensados, planejados, operacionalizados. Ainda acompanhando 0 autor, as escolas, ao reproduzirem um currículo arborescente, acabam percebendo que, mediante a tantas fragmentações, os estudantes não conseguem perceber a totalidade e, com isto, sentem dificuldades em articular os saberes que Ihes foram ensinados de forma fragmentada. Nesse sentido, a fala de uma das professoras da escola exemplifica bem essa situação quando diz que:

não adianta a gente querer exigir destes meninos que eles saibam fazer uma leitura de realidade, pois eles não conseguem ligar as coisas... Eles não prestam atenção em aula. Quando não estão de olho no celular, estão na conversa. O objetivo deles é, no máximo, decorar o que cada professor ensina pra passarem nas provas. Agora, fazer uma leitura da complexidade social é bem difícil, viu`?

As dificuldades dos estudantes em analisar a realidade, apontadas pela professora, revela, para além de uma estrutura curricular fragmentada, hierarquizada, serializada, a presença do legado iluminista e sua utopia em atribuir à escola a função de formar os educandos para o exercício consciente da cidadania. Razão e ciência (o uso da razão científica) constituem-se em condições definitivas para que o sujeito pensado pelo iluminismo possa alcançar o verdadeiro conhecimento, a vivência harmoniosa em sociedade, a liberdade, a felicidade. Como argumentou Foucault (1994, p. 176), "[...] as luzes que descobriram as liberdades inventaram também as disciplinas".

A crença na salvação dos sujeitos, por meio da aquisição dos conhecimentos científicos, acrescida da direção das condutas no sentido correto, permanece regendo a racionalidade da escola contemporânea. Utilizando-se de um discurso voltado à formação da cidadania, da autonomia, da liberdade de escolhas, da tolerância, da igualdade, os discursos pedagógicos colocam em circulação um ideal de sujeito que não encontra ressonâncias no contexto escolar. Isso porque, ao mesmo tempo em que a escola protege, incluí, acolhe, ela impõe obediência, resiliência,

\footnotetext{
${ }_{9}$ Relato de um dos professores da escola estudada.
} 
resignação, conformação das multiplicidades a um modelo normativo que facilite o ordenamento e o controle das diferenças.

Inscrita nesse solo discursivo, a escola vem sofrendo os abalos dos "novos tempos", vivenciando crises produzidas pelas novas configurações de forças que, pouco a pouco, adentram os cotidianos escolares. Por certo, esses fluxos de forças ainda não causaram rupturas com as disciplinas nas escolas. São forças que coexistem e disputam sentidos nos cotidianos escolares. Produzem um conjunto de sentimentos que circulam pela escola numa espécie de disputa pela identificação das dimensões que possam estar causando tamanha instabilidade.

Na realidade estudada, as professoras e professores compreendem a escola como um local de inclusão social, de formação para o trabalho e de preparação para a vida em sociedade. Nas palavras de uma das professoras:

A escola é um dos únicos lugares de inclusão social que esses meninos têm na vida. Ou eles aprendem aqui ou serão mais marginalizados do que já são. É muito triste conviver com esta juventude negra, pobre, excluída, cheia de necessidades e muito pouco poder fazer. A gente se esforça por passar os conhecimentos, criar novas estratégias pedagógicas, fazer com que eles aprendam e sejam alguém na vida, mas as carências são muitas... A gente tem que cumprir com os conteúdos curriculares, não tem outro jeito. Somos cobradas o tempo inteiro, tanto na escola, quanto pela própria Secretaria de Educação. Eu já não consigo mais trabalhar no noturno, estou doente com tudo o que vejo aqui. Quero mudar de turno antes que eu morra de tanta angústia!

$\mathrm{Na}$ concepção dos estudantes, a escola representa um mal necessário, uma forma de construir redes de sociabilidade, de progredir na vida e competir no mercado de trabalho, conforme declarou um estudante, ao ser questionado se gostava da escola:

para mim, a escola é uma obrigação. Eu não gosto. Mas, sei que preciso estudar para ser alguém na vida (risos). Gosto mesmo é quando os professores faltam e a gente pode ficar no pátio conversando com os colegas ou fazendo o que tiver vontade. 
No que diz respeito às relações estabelecidas no espaço escolar, os relatos dos professores e das professoras identificam alguns fatores que concorrem para que a escola tenha dificuldades em estabelecer relações mais amigáveis entre as pessoas de sua comunidade. Dentre eles: a falta de respeito, a ausência de bons modos, a agressividade no tratamento com os colegas e com os docentes, a pouca valorização atribuída aos estudos e o descomprometimento com as atividades escolares, a violência social, a inserção no tráfico de drogas, a utilização de drogas, dentre outras. Estaríamos assistindo à entrada de um novo regime de poder atuando nas escolas? A recorrente denúncia de falta de segurança, relatada tanto pelos/as estudantes, quanto por professores/as, incluindo manifestações favoráveis à militarização das escolas, seria certo saudosismo aos tempos de atuação do poder disciplinar?

Nos rastros das sociedades disciplinares examinadas por Foucault, Deleuze (1992, p, 220) anuncia a crise das disciplinas (já previstas pelo próprio Foucault), "[...] em favor de novas forças que se instalavam lentamente e que se precipitariam depois da Segunda Guerra mundial: sociedades disciplinares é o que já não éramos mais, o que deixávamos de ser". No entendimento de Deleuze (1992), trata-se de uma crise generalizada que engloba todos os meios de confinamento (prisão, hospital, fábrica, escola, família), iniciados nos séculos VIII e XIX, cujo apogeu deu-se no século XX. Para o autor, a gestão dessa crise dar-se-á por meio de constantes reformas nos diferentes setores. Reformar a reforma será o trabalho dos governantes em busca do controle e da estabilidade dessas instituições que, até então, haviam respondido com efetividade aos caprichos do capital e sua crescente demanda pela produção de corpos dóceis e uteis, necessários ao avanço do capitalismo.

Deleuze (1992, p. 216) afirma que "[...] estamos entrando nas sociedades de controle, que funcionam não mais por confinamento, mas por controle contínuo e comunicação instantânea". Já não se trata de um tipo de poder que, a um só tempo, individua e massifica, ou ainda, "[...] molda a individualidade de cada membro do corpo" (DELEUZE, 1992, p.220). 
Nas sociedades de controle, a economia do poder assume uma outra racionalidade. Agora, o controle, ao contrário das sociedades disciplinares, não requer mais espaços fechados para se exercitar. Dessa forma, se nas sociedades disciplinares o poder operava por confinamento, concentrando pessoas, distribuindo-as no espaço, ordenando-as no tempo, hoje, os exercícios de poder dão-se a céu aberto. Ou seja, já não há mais a necessidade de enclausurar para governar.

Uma consequência importante da configuração do poder nas sociedades atuais é que, se antes o sujeito não cessava de passar de um espaço fechado a outro (escola, quartel, fábrica etc.), hoje, deixamos os diferentes espaços fechados pelos quais passamos com a nítida sensação de que não terminamos nada. "O homem não é mais o homem confinado, mas o homem endividado" (DELEUZE, 1992, p.221). Esse sentimento contemporâneo de estarmos sempre em dívida (não apenas financeira) explica-se, em grande parte, pelo transbordamento das fronteiras das instituições sociais que antes operavam em espaços fechados. Por efeito, as relações entre a sociedade e a subjetividade foram afetadas por todo um conjunto de novas tecnologias de poder que interferem diretamente nas formas pelas quais as subjetividades são construídas.

O autor argumenta que "[...] tentam nos fazer acreditar numa reforma da escola, quando se trata de uma liquidação". Ao defender que os controles são uma modelação, "moldagem auto-deformante". Aposta que a educação afastar-se-á cada vez mais da necessidade de ser realizada em espaços fechados em favor "[...] das formas de controle contínuo, avaliação contínua, e a ação da formação permanente sobre a escola, o abandono correspondente de qualquer pesquisa na Universidade, a introdução da "empresa" em todos os níveis de escolaridade" (DELEUZE, 1992, p.225).

Nesse sentido, a transição das sociedades disciplinares para as sociedades de controle faz-se acompanhada de transformações no modo de produção capitalista no qual as conquistas do mercado já não necessitam mais da disciplina e sim da tomada de controle. A mudança do foco mercadológico, ou seja, da produção de bens de consumo à "criação 
de mundos" (LAZZARATO, 2006, p. 99), permitiu que a fábrica cedesse lugar à empresa. E, ao contrário do modelo fabril, onde o poder operava a partir da concentração dos/das operários/as em um espaço fechado, "[...] a empresa introduz o tempo todo uma rivalidade inexpiável como sã emulação, excelente motivação que contrapõe os indivíduos entre si e atravessa cada um, dividindo-o em si mesmo" (DELEUZE, 1992, p. 220). Nesse contexto, o marketing torna-se instrumento de controle social e a mídia exerce uma função primordial na disseminação/produção das competências mercadológicas necessárias ao perfil profissional do "sujeito contemporâneo" não pertence à fábrica e, sim, a empresa. Ele é produzido como um sujeito flexível, autônomo, criativo, inovador e livre.

As transformações apontadas por Deleuze já são facilmente identificadas no campo da educação e nas instituições de ensino. Basta observar a entrada massiva da educação à distância nos processos de formação, em especial, no nível universitário, mas também para a formação no nível médio dos estudantes trabalhadores; as formações continuadas (capacitações, reciclagens, atualizações, especializações) para professores/as; ranqueamentos de escolas; políticas curriculares com intervenções diretas na distribuição dos conhecimentos escolares e na própria arquitetura curricular.

De fato, toda essa série de acontecimentos está mudando os cotidianos escolares e levando-nos, enquanto sujeitos da educação, a certa desorientação diante da perda dos referenciais que tínhamos. Essas dimensões dificultam a identificação de uma geografia do dizível e do visível nos contextos escolares contemporâneos, na medida em que as estratificações (DELEUZE; GUATARRI, 1996, 1997) deixam de existir como possibilidade de identificarmos com mais clareza as territorialidades constituídas nas realidades escolares. Tempos difíceis!

No entanto, precisamos admitir que a escola, assim como a árvore sapucaia, apesar da vulnerabilidade dos novos tempos, mantém-se no centro do pátio, oferecendo sombra e colorido para a escola. Mas, quais as condições de possibilidade de sobrevivência da sapucaia frente aos 
vendavais produzidos por todo um conjunto de dispositivos voltados à normalização, homogeneização e controle? Não me proponho a responder tal questão, até porque ela remete de certa forma, a um exercício de futurologia. Porém, o que a pesquisa aponta é que a escola continua sendo um espaço profícuo na constituição de redes de sociabilidade, resistências e emergência da diferença.

\section{ENTRE SAPUCAIAS E FISSURAS}

É certo que a metáfora da árvore dos saberes representa muito bem as formas pelas quais os currículos escolares são pensados, planejados, estruturados e praticados pela grande maioria das escolas brasileiras. Sobre isso, o professor Silvio Gallo (2007), de forma muito apropriada, discorre sobre o "currículo (entre) imagens e saberes", mostrando-nos o quanto a escola e o próprio currículo permanecem herdeiros de uma compreensão de mundo e de conhecimento que necessita ser fragmentado para que possa ser compreendido. Segue a lógica instaurada na antiguidade de que 0 conhecimento da totalidade não estaria ao alcance do "espírito humano". Fragmenta-se em partes como possibilidade de vir a conhecer o todo.

Na modernidade, com a criação dos métodos científicos, essa lógica da divisão e subdivisão do conhecimento por áreas ganha grandes proporções e, "[...] num movimento intenso de especialização, vão se subdividindo e criando novas áreas" (GALLO, 2007, p.5). Nesse contexto, a imagem da árvore dos saberes'10 (criação de Descartes) tornou-se interessante para dar visibilidade à estrutura e organização dos conhecimentos. Instaura-se a divisão disciplinar como lógica curricular, cuja racionalidade estende-se aos dias atuais.

\footnotetext{
10 Nessa imagem, as raízes da árvore representariam o mito, como conhecimento originário; o tronco representaria a filosofia, que dá consistência e sustentação para o todo; os galhos, por sua vez, representariam as diferentes disciplinas científicas, que, por sua vez, subdividemse em inúmeros ramos. Interessante notar que a imagem da árvore, por mais que dê vazão ao recorte, à divisão e às subdivisões, remete sempre de volta à totalidade, pois há uma única árvore e, para além do conhecimento das partes, podemos chegar ao conhecimento do todo, isto é, tomando distância, podemos ver a árvore em sua inteireza (GALLO, 2007, p.6).
} 
É bem verdade que essa divisão dos saberes em disciplinas vem ocupando a agenda de trabalho de um universo significativo de estudiosos do campo da educação, na busca por alternativas teórico/práticas que permitam uma nova imagem de currículo. Uma parcela significativa desses estudos, no entanto, centra suas preocupações na remodelagem da árvore (religar saberes pela interdisciplinaridade, transdisciplinaridade, multidisciplinaridade, pluridisciplinaridade etc.), porém, sem causar rupturas à árvore.

Em conformidade com Gallo (2007), "[...] não há "religação dos saberes" a ser perseguida, pois não há como "religar" o que nunca esteve ligado. Ao contrário, o que precisamos buscar são formas de diálogo na diferença, diálogo na multiplicidade, sem a intenção de reduzir os diferentes ao mesmo, ao uno." Romper com a ilusão da unidade, da existência de uma única realidade é apostar na multiplicidade. Na verdade, como nos alertaram Deleuze e Guatarri (2000, p.11):

[...] não basta dizer viva o múltiplo, grito de resto difícil de emitir. Nenhuma habilidade tipográfica, lexical ou mesmo sintática será suficiente para fazê-lo ouvir. É preciso fazer o múltiplo, não acrescentando sempre uma dimensão superior, mas, ao contrário, da maneira mais simples, com força de sobriedade, no nível das dimensões de que se dispõe, sempre n-1 (é somente assim que o uno faz parte do múltiplo, estando sempre subtraído dele). Subtrair o único da multiplicidade a ser constituída; escrever a n-1. Um tal sistema poderia ser chamado de rizoma.

O currículo, a partir da imagem do rizoma (currículo rizomático), rompe definitivamente com a imagem de currículo - árvore. Um rizoma é um sistema aberto, um lugar de passagem, sem centralidade, sem periferia, sem início, sem fim. Ao contrário, atribui à multiplicidade seus direitos e seus variados sons. Por efeito, rompe com o famoso "fio condutor" das práticas pedagógicas, bem como não faria sentido trabalhar com predefinições, planejamentos e suas listagens intermináveis de objetivos a serem alcançados. Ao contrário, supõe encontros imprevisíveis, contingenciais. Em síntese: 
Se o currículo disciplinar remete-nos para uma "pedagogia da ordem", que investe em hierarquias, planejamentos, organizações, controle, um currículo rizomático, por sua vez, implica numa "pedagogia do caos", isto é, um processo educativo que escape ao controle, traçando linhas de fuga, que rompa hierarquias, que desfaça planos prévios. Aventurar-se, sem bússola, pelos mares da multiplicidade dos saberes (GALLO, 2007, p.8).

Em que pese a minha aposta na potência de um currículo rizomático e o desejo de que a educação aposte na multiplicidade em detrimento da homogeneização, o fato é que os currículos escolares continuam sendo estruturados e praticados sob o julgo das disciplinas, das normatizações, do controle e da regulação. Diante disto, como compreender o que nos diz a estudante, a exemplo de tantos outros estudantes, da escola pesquisada? vamos ouvi-la:

Eu não gosto da organização da escola e de alguns professores, porém eu respeito. Mas, eu acho a escola top, porque tem muita diversidade dentro dela... quando entrei aqui, eu tinha outra forma de pensar, hoje já penso diferente. Ter contato com pessoas diferentes é muito bom, pois você acaba criando uma nova maneira de pensar.

Esse relato ecoa entre muitos/muitas outros/outras estudantes, ao identificarem a "organização" da escola como enfadonha, chata, pouco atrativa, com poucos espaços para a participação dos alunos, com aulas monótonas, conteúdos trabalhados sem criatividade. No entanto, consideram a escola top por identificá-la como um lugar de encontro com colegas, de troca de cumplicidades entre amigos, de paquera, de articulação política, de contato com a "diversidade", de preparação para o prosseguimento nos estudos e para o mercado de trabalho.

Esses jogos de forças (poder e resistência) forçam-nos a pensar que, embora, a escola e o currículo venham constantemente operando para produzir sujeitos com "competências" e "habilidades" adequadas às atuais necessidades do capitalismo e do tipo de sujeito a ele correlato, não se pode deixar de considerar que existem linhas de fuga, movimentos de 
desterritorializações, fluxos nômades que, dependendo do agenciamento de suas forças, poderão criar novas formas de resistências aos efeitos do poder normalizador e disciplinador que circula na escola e no currículo. Parafraseando Hardt e Negri (2005), a multidão (o lado monstruoso) nasce dentro do império e a ele se opõe.

Dito de outra maneira há a coexistência de dois vetores de força atuando nas segmentações. "A árvore é filiação, mas o rizoma é aliança, unicamente aliança. A árvore impõe o verbo "ser", mas o rizoma tem como tecido a conjunção "e... e... e..." Há nesta conjunção força suficiente para sacudir e desenraizar o verbo ser" (DELEUZE e GUATTARI, 2000, p.35). Em poucas palavras, há rachaduras, linhas de força, fluxos que escapam, fogem, desterritorializam, enfim, desobedecem a lógica perversa dos mecanismos de homogeneização e controle presentes na escola e no currículo.

\section{CURRÍCULO: CAPTURAS E FUGAS}

Levando em consideração às reflexões apresentadas até aqui, busco, a partir de três situações extraídas da pesquisa, pensar sobre as brechas, fissuras, rachaduras, deixadas pelo currículo que possam exemplificar fugas frente às imposições da ditadura da identidade prêt-à-porter em tempos do predomínio "neoliberal no mercado, escolha e accountability"? (YATES, 2010, p.6. apud MACEDO, 2017, p.544).

\subsection{O "NOVO" ENSINO MÉDIO}

O "novo Ensino Médio" chegou às escolas da rede estadual de ensino do Estado da Bahia, a partir da seleção de algumas escolas pilotos, com o objetivo de implementar, em caráter experimental, as mudanças curriculares no ensino médio, propostas pela Lei $n^{\circ} 13.415 / 2017$. Dentre as instituições selecionadas, encontra-se a escola que faz parte da pesquisa. Essa indicação foi informada ao coletivo docente da escola, no início do ano letivo de 2019 e, desde então, vem sendo pauta recorrente de discussão 
entre os/as professores em reuniões de áreas, na sala de professores, nos corredores.

Eu não concordo que tenhamos que mudar tudo em função do autoritarismo deste governo que nem mesmo conhece a realidade da nossa escola. Afinal, tudo o que se lê sobre essa reforma indica ser um retrocesso... um retorno aos tempos tecnicistas, da divisão de estudantes em função de suas origens... sou contra e penso que deveríamos não aceitar esta imposição. Afinal, quais foram os critérios para que tenhamos sido escolhidos 11 ?

Eu também acho que deveríamos recusar. Só nos oferecem trabalho. Salário e melhores condições, ninguém fala. Da minha parte, não mudarei nada no meu planejamento. Se vocês aceitarem, se virem para dar conta. Eu, fora! Vamos ganhar o quê? Vocês sabem que aumenta a carga horária (referindo-se a reforma do ensino médio), não é? E quem dará conta disso? E quem garante que essa coisa aí (a reforma) seja aceita pelos alunos? Ou, mais uma vez, vamos enfiar garganta abaixo ${ }^{12}$ ?

Angústias, revoltas, resistências e o anseio de encontrar saídas que possam apontar formas alternativas de (re)existir ao conjunto de prescrições normativas e suas interferências diretas sobre a escola, seus sujeitos e suas práticas são marcas fortes encontradas nos depoimentos colocados acima e de muitos outros/outras que igualmente se manifestaram em oposição à verticalização das tomadas de decisão que se dão tanto no nível macropolítico quanto no espaço da escola.

Observa-se nos relatos, que os/as professores/as sentem dificuldades em gerar fluxos de resistência que não estejam amarrados aos condicionantes externos, no caso, às políticas macrossociais. Por efeito, os/as professores aproximam-se muito mais da figura do "professor profeta" do que propriamente do "professor militante", descrito por Gallo (2007, p. 171) "[...] como aquele que procura viver as situações e dentro dessas situações vividas produzir a possibilidade do novo". De fato, ainda somos, em grande medida, modernos! A utopia em querer transformar o mundo pelo "desvelamento" da realidade acaba por apaziguar o potencial criativo da resistência. Rouba-lhes suas forças inventivas e criativas.

No entanto, em que pesem as armadilhas do poder (sempre tão perspicazes!) e as dificuldades em opor-se ao estabelecido, no interior da

\footnotetext{
${ }^{11}$ Depoimento de uma das professoras da escola.

12 Relato de uma das professoras da escola.
} 
instituição, penso que haja na reflexão da professora Maria ${ }^{13}$, o desejo de desestabilizar as evidências, de provocar desterritorializações, ou, talvez, de produzir a possibilidade do novo:

O problema é que Lei! Nenhuma escola escapará. Mais cedo ou mais tarde, todas terão que se adaptar. Eu não concordo também, aliás, não vou mentir, eu nem conheço muito bem essa reforma para além do marketing feito pelo governo antes da aprovação. Mas, vejo que fazer parte do projeto-piloto pode ser uma possibilidade de mostrarmos as falhas, apontarmos as impossibilidades de seguir com este modelo de reforma.

Percebe-se na fala da professora, a coexistência de forças que se misturam, embaralham-se e produzem movimentos que oscilam entre a busca pela estabilidade, territorialização do espaço institucional, e linhas de fugas que descodificam e desterritorializam. O desafio é pensar os fluxos de resistência e suas intensidades nos movimentos de desterritorialização. Como nos advertiram Deleuze e Guattari (1977, p. 125), são os "[...] perigos da luta minoritária; reterritorializar-se, refazer fotos, refazer o poder e a lei, refazer também a grande literatura". Ou, no caso, refazer (ou retornar) ao currículo maior.

\subsection{PROJETO DE VIDA}

De acordo com os discursos da Secretaria Estadual da Educação, cada estado tem autonomia para construir o reordenamento curricular a ser apresentado para o MEC. Nesse sentido, as negociações entre a escola e a Secretaria Estadual de Educação resultaram, para o ano de 2019, em arranjo curricular que, embora, tenha garantido a manutenção da organização curricular, anteriormente planejada, deverá ser acrescida uma espécie de "eixo temático" para as turmas do primeiro ano do ensino médio. A ideia da Secretaria de Educação é a de que até 2022, o "novo ensino médio" esteja já completamente implantado, sendo que, a partir de 2020, o currículo já será estruturado por eixos temáticos, impondo, por consequência, outra arquitetura curricular.

13 Utilizo um nome fictício como recurso de escrita. 
O "Guia de Implantação do novo ensino médio", elaborado pelo Ministério da Educação (MEC), em parceria com o Fórum Nacional dos Conselhos Estaduais de Educação (FNCEE), com o Conselho Nacional dos Secretários de Educação (CONSED) e Secretarias Estaduais de Educação, foi distribuído para as escolas-pilotos com o "propósito de apoiar as redes e sistemas de ensino, sugerindo caminhos para a construção de uma nova estrutura para a etapa do Ensino Médio" (BRASIL. Guia de Implantação do novo ensino médio. s/d). Apresenta aos/às professores/as da educação básica, uma espécie de passo a passo da reforma. Nele, a reforma do ensino médio é apresentada como a salvação do futuro da educação nacional em oposição ao "antigo" ensino secundarista, cuja "desconexão entre os anseios da juventude e o que a escola exige dela manifesta-se nos indicadores de frequência e desempenho." (ib).

Mobilizando o discurso da apologia do jovem com poder decisório sobre suas próprias escolhas, o guia afirma que "[...] a espinha dorsal do Novo Ensino Médio é o protagonismo juvenil, que estimula o jovem a fazer escolhas, tomar decisões e se responsabilizar por elas" (BRASIL. Guia de Implantação do novo ensino médio. $s / d$ ). O documento traz as principais mudanças propostas pela reforma: a BNCC; a ampliação da carga horária; a formação técnica e profissional no ensino médio regular e a escolha de percursos formativos.

A escolha de percursos formativos, considerada como o primeiro movimento em prol da reforma curricular nas escolas pilotos da Bahia, parte do pressuposto que os currículos do Novo Ensino Médio terão uma parte referenciada na BNCC (formação geral básica), sendo que:

[...] são os itinerários formativos, que oferecem caminhos distintos aos estudantes, ajustados às suas preferências e ao seu projeto de vida, cuja oferta considera as possibilidades de escolas e redes. É principalmente na escolha do itinerário, portanto, que se materializa o protagonismo juvenil (BRASIL. Guia de Implantação do novo ensino médio. s/d). 
O protagonismo juvenil, propagado pelos discursos do projeto reformista do ensino médio, constitui-se em uma estratégia de poder em que o novo trabalhador/empresário (esse jovem que toma decisões e se responsabiliza por elas) deverá fabricar-se a si mesmo por meio de um conjunto de dispositivos informacionais, desdobrados em competências cognitivas, corporais, comunicacionais, socioemocionais, de modo a torná-lo um empreendedor de si mesmo. É a produção do novo sujeito - o sujeito empresário - das sociedades de controle, anunciadas por Deleuze.

O "projeto de vida" foi tema de discussão entre os/os professores/as da escola em diversas reuniões de planejamento por áreas de conhecimento (ACs) que se prolongaram pelos corredores, refeitório, intervalos de aulas e em conversas, mais reservadas, com os/as colegas com maior afinidade na tentativa de construir consensos sobre a melhor forma de trabalhar com os projetos de vida.

Já que podemos criar esse eixo, podemos propor oficinas onde os alunos possam expressar a partir de diferentes linguagens seus projetos de vida. Até porque os primeiros anos não sabem o que querem ser na vida... acho um atropelamento essa ideia de ir forçando os alunos a escolherem essa ou aquela área ${ }^{14}$.

Neste primeiro momento, não precisamos fazer com que os estudantes escolham nada... tem que ser atividades lúdicas, livres, onde eles possam expressar o que estão sentindo no presente e não necessariamente o que tenham que fazer no futuro. Podemos organizar passeios, visitar as universidades, conhecer de perto 0 mundo do trabalho, as profissões ${ }^{15} \ldots$

Percebo, nas reflexões das professoras, vetores que deslocam, desorganizam a ideia de submissão do "projeto de vida" aos discursos reformistas, cujos ideais de sujeito (flexível, empreendedor, inovador, responsável por suas escolhas), e de modos de vida, são produzidos como verdades universais (idênticas, excluídos os desviantes: negros/negras, índios/índias, gays, dentre outros) que deve ser seguidas por todos, em conformidade com a racionalidade política que caracteriza as sociedades neoliberais.

\footnotetext{
14 Relato de um dos professores da escola.

15 Depoimento de um professor da escola.
} 


\subsection{NOVEMBRO NEGRO OU "QUE 'NEGRO' É ESSE NA CULTURA NEGRA 16"?"}

Inicialmente, é preciso dizer que a BNCC trata as relações ÉtnicoRaciais como "diversidades", seguindo a trilha aberta por outros dispositivos legais que orientam, prescrevem, normatizam os currículos e recorrem a essa noção para "incluir" todos os supostos desvios. Na BNCC, a noção de diversidade integra três, do conjunto das dez "competências gerais", que indicam as "aprendizagens essenciais" prescritas pelo MEC.

O conceito de "diversidade" presente nas três competências em que o termo é utilizado inscreve-se em um discurso moralizante segundo o qual a diversidade parece apresentar condições de riscos. Por exemplo, na competência (seis), a "valorização da diversidade de saberes e vivências culturais" encontra-se atrelada e limitada ao mercado de trabalho. As "escolhas alinhadas ao exercício da cidadania e ao seu projeto de vida, com liberdade, autonomia, consciência crítica e responsabilidade". Ou seja, a diversidade encontra-se normalizada ao exercício da cidadania (branca) e aos padrões do mercado e seus "perfis profissionais" (homem, branco, heterossexual).

Por sua vez, a competência (oito) vai falar em "diversidade humana", relacionando-a com a saúde física e emocional e o cuidado em reconhecer as "suas emoções e as dos outros, com autocrítica e capacidade para lidar com elas." É interessante observar as capturas do poder nas sociedades de controle e suas incidências sobre os corpos (malhados e esculpidos a partir da primazia do idêntico) e suas conexões com as estratégias de marketing que disseminam, em alta escala, um conjunto de mercadorias colocados à disposição das pessoas negras e, muito especialmente, das mulheres em séries que obedecem aos padrões da uniformidade.

Por fim, a competência (nove) relaciona diversidade com tolerância, empatia, respeito aos direitos humanos, identidades e culturas. Aqui, repetese o discurso, tantas vezes dito nos cotidianos escolares, da necessidade da tolerância, da empatia, pois, "todos são iguais", ou ainda, uma versão

\footnotetext{
16 Utilizo aqui a pergunta formulada por Stuart Hall no livro Da diáspora (HALL, 2003, p.317).
} 
atualizada do mito da democracia racial. Em todo o caso, a diversidade deve seguir a norma, domesticar seus monstros, docilizar suas asperezas. Uniformizar a diversidade, excluir, tanto quanto possível, a diferença. Adestrar o espírito!

Na escola, as/os professoras/es admitem que exista racismo:

Apesar da maioria ser negra, sempre tem aqueles que fazem brincadeirinhas de cunho racista. Nós trabalhamos o racismo tanto quanto podemos. Só não podemos fazer mais porque precisamos dar conta dos conteúdos... Não tem como fazer diferente ${ }^{17}$.

A discussão do racismo na escola, quase sempre, é atravessada pela possibilidade de atribuir ao outro as ações e posturas racistas. Os/as professores/as não se admitem como pessoas que possam exercer o racismo em suas práticas. Da mesma forma, os/as estudantes. Porém, não se colocam no lugar de antirracistas. Aqui, vale lembrar as potentes palavras de Deleuze e Guattari (1977, p. 31), quando dizem:

Do ponto de vista do racismo, não existe exterior, não existem as pessoas de fora. Só existem pessoas que deveriam ser como nós, e cujo crime é não o serem. A cisão não passa mais entre um dentro e um fora, mas no interior das cadeias significantes simultâneas e das escolhas subjetivas sucessivas. O racismo jamais detecta as partículas do outro, ele propaga as ondas do mesmo até à extinção daquilo que não se deixa identificar (ou que só se deixa identificar a partir de tal ou qual desvio). Sua crueldade só se iguala a sua incompetência ou a sua ingenuidade.

A escola trabalha as questões raciais a partir dos marcadores que operam como unidades que homogeneízam, uniformizam e produzem a representação social do negro. Como disse a professora, em uma das conversas que tivemos sobre a educação racial na escola:

Você sabe que dedicamos, em novembro, uma semana inteira de atividades voltadas para a cultura afro e afro-brasileira. Fazemos diferentes atividades: conferências sobre a África, ancestralidade, oficinas de turbantes, capoeira, desfile e concurso da beleza negra, culinária afro e por aí vai.

\footnotetext{
17 Depoimento de uma das professoras da escola.
} 
Aqui, duas observações: uma delas, é que a escola trabalha racismo em bloco. Concentra suas atividades na semana que inclui o dia da consciência negra, 20 de novembro. Todos os outros dias, os/as estudantes negros/as são invisibilizados pela cultura branca e seus marcadores sociais. A outra remete aos marcadores sociais que são utilizados para trabalhar as questões raciais. É recorrente a representação do/da negro/a como escravo/a, como pessoa assujeitada aos caprichos dos senhores dos engenhos.

Essa fixação da representação do/a negro/a às raízes históricas da escravidão brasileira, bem como a referência à África como um bloco homogêneo desconsidera que "[...] somos nós, em sociedade, entre culturas humanas, que atribuímos sentidos às coisas. Os sentidos, consequentemente, sempre mudarão de uma cultura para outra e de uma época para outra" (HALL, 2000, p. 130). Ademais, contribui para fortalecer a lógica escravista.

Uma das professoras, ao discutir os "projetos de vida" a serem adotados pela escola, fez o seguinte depoimento:

Imaginem esses meninos pobres, negros, sobreviventes ... que projeto de vida podem ter? Se souberem que o ensino médio técnico poderá lhes dar a chance de ter um empreguinho qualquer, claro que se jogam... É muito triste dizer, mas se está difícil pro menino branco conseguir um emprego, imaginem pra eles... aqui, a grande maioria vai querer ser técnico. É a saída mais rápida para eles ${ }^{18}$.

Nota-se que há um enclausuramento das possibilidades da pessoa negra como se o seu projeto de vida já estivesse pré-determinado pelos marcadores sociais da cultura branca. Como nos adverte Stuart Hall (2003, p. 345), "Negro" não é uma categoria de essência numa direção à homogeneidade, existe um conjunto de diferenças históricas e experiências que devem ser consideradas e que localizam, situam e posicionam o povo negro.".

Frente às tentativas das práticas curriculares em racializar o/a negro/a e o corpo negro, penso que a reflexão, transcrita a seguir, traga elementos

\footnotetext{
18 Depoimento de uma das professoras da escola estudada.
} 
que fragmentam as certezas e as verdades sobre o corpo negro. Talvez, o esfarelamento dos marcos representacionais da identidade negra abra espaços para o jogo das diferenças.

Aqui, na escola, negro só é gente no dia da consciência negra. Eles fazem um evento de desfile, como se quisessem dizer: Ho! existe beleza negra, viu? E isso acaba sexualizando as meninas. Acho que deveria ser um ato que nos valorizasse, mas o efeito é ao contrário. Os meninos ficam nos chamando de gostosa e outras palavras que nos ofendem enquanto mulheres ${ }^{19}$.

Para fechar o texto, reporto-me aqui a um depoimento/imagem vivida na escola. Uma das turmas do segundo ano do ensino médio teria que esperar por dois períodos de aulas justificados pela ausência da professora que estava doente. A direção da escola ofereceu duas possibilidades para os/as estudantes: poderiam dividir-se em pequenos grupos e assistir as aulas de português em outras turmas ou ocupariam o tempo na biblioteca. Entre conversas, risadas e algumas correrias, percebi que os/as estudantes haviam se distribuído entre as opções sugeridas. Transcorridos cerca de trinta minutos dirigi-me ao pátio de acesso à saída da escola e deparei-me com um grupo de estudantes que, em um tom baixo, dançavam e cantavam um hip hop. Aproximei-me deles e escutei a música com mais nitidez:

\begin{abstract}
Negro drama / entre o sucesso e a lama / Dinheiro, problemas, inveja, luxo, fama / Negro drama / Cabelo crespo e a pele escura / a ferida, a chaga, à procura da cura / Negro drama / Tenta ver e não vê nada / a não ser uma estrela / longe, meio ofuscada / Sente o drama, o preço, a cobrança / no amor, no ódio, a insana vingança / Negro drama / Eu sei quem trama e quem tá comigo / o trauma que eu carrego / pra não ser mais um preto fodido [... $]^{20}$.
\end{abstract}

Enquanto, eu me fazia elucubrações teóricas diante do que via/ouvia, fui interpelada por um dos estudantes do grupo: "gostou pró? É muito irada essa letra! Vamos pedir pra fazer uma apresentação no novembro negro. É muito maneiro".

\footnotetext{
19 Estudante da escola estudada. Cursa o 3. ano do ensino médio.

20 Letra do Rap Negro Drama. Racionais MC's.
} 


\section{PARA FECHAR O TEXTO: ALGUMAS SINALIZAÇÕES NECESSÁRIAS}

Pensar na perspectiva da diferença desloca o interesse em saber se os conhecimentos trabalhados pelo currículo valorizam ou não determinados saberes em detrimento de outros. Já não se trata de identificar se o currículo trabalha criticamente (ou não) os saberes das culturas afro-brasileiras e quais seus efeitos para o fortalecimento da identidade negra na escola.

É certo que os currículos são brancos, eurocêntricos, machistas e heteronormativos, mas, no entendimento da diferença, o interesse fica por conta de acompanhar os movimentos de fugas, desterritorializações, criações de novos modos de existência. Nesse sentido, a lógica da identidade e do auto-reconhecimento torna-se menos interessante, pois, é na proliferação de forças que subvertam a ideia de um currículo que opera pela totalidade e a unidade que brechas podem ser abertas para a criação de outros e novos desenhos curriculares.

Ao se apostar nas resistências como forças que desterritorializam, questionam e subvertem as normas, é possível identificar movimentos que permitem escapar das armadilhas das identidades fixadas pelas normativas institucionais desestabilizando os caprichos das relações de poder e seus efeitos sobre os corpos negros, posto que permitem a emergência das singularidades.

Neste sentido, embora uma parte expressiva dos estudos que discutem currículo e relações étnico-raciais centre suas problematizações nas amarras produzidas nessas relações, talvez, ao deslocarmos nossas miradas de pesquisa para as formas pelas quais os sujeitos resistem, reinventam maneiras de estar na escola e viver seus rituais institucionais, consigamos perceber que para além das imposições e dos submetimentos existem brechas que abrem novas formas de existência.

\section{REFERÊNCIAS BIBLIOGRÁFICAS}

BRASIL. Lei 11.645/08 de 10 de março de 2008. Diário Oficial da União, Poder Executivo, Brasília, 2008. 
BRASIL. Lei n 10.639, de 9 de janeiro de 2003. Diário Oficial da União, Poder Executivo, Brasília, 2003.

BRASIL. Ministério da Educação. Base Nacional Comum Curricular - BNCC. Disponível em:

<http://basenacionalcomum.mec.gov.br/wpcontent/uploads/2018/04/BNC C_EnsinoMedio_embaixa_site.pdf >. Acesso em 04 abr. 2018.

CORAZZA, S. E TADEU, T. Composições. Belo Horizonte, Brasil: Autêntica, 2003.

DELEUZE, G. Diferença e repetição. São Paulo: Graal, 1988.

DELEUZE, G. Post-scriptum sobre as sociedades de controle. In:

Conversações: 1972-1990. Rio de Janeiro: Ed. 34, 1992. p. 219-226

DELEUZE, G; GUATTARI, F. Mil Platôs: capitalismo e esquizofrenia. v. 3. Rio de Janeiro: Ed. 34, 1997.

DELEUZE, G; GUATTARI, F. Mil Platôs - Capitalismo e Esquizofrenia. v. 1. Rio de Janeiro: Ed. 34, 2000.

DELEUZE, G.; GUATTARI, F. Kafka: Por uma Literatura Menor. Rio de Janeiro: Imago, 1977

FOUCAULT, M. Vigiar e Punir: nascimento da prisão. Petrópolis: Vozes, 1994.

GALLO, S. Em torno de uma educação menor. Educação e Realidade, Porto Alegre, v.27, n.2, 2002. p.169-178.

GALLO, Sílvio. Currículo (entre) imagens e saberes. Palestra proferida no V Congresso Internacional de Educação. Anais do Congresso Internacional de educação. São Leopoldo, 2007.

HALL, S. Da Diáspora: identidades e mediações culturais. Belo Horizonte: UFMG; Brasília: UNESCO, 2003.

HALL, S. A identidade cultural na pós-modernidade. 7. ed. Rio de Janeiro: DP\&A, 2003.

HALL, S. Quem precisa da identidade? In: SILVA, T. T. (Org.). Identidade e diferença: a perspectiva dos estudos culturais. Petrópolis, Rio de Janeiro: Vozes: 2000. p.103 - 133.

HARDT, M; NEGRI, A. Multidão: guerra e democracia na era do império. Rio de Janeiro: Record, 2005.

LAZZARATO, M. As revoluções do capitalismo. Rio de Janeiro: Civilização Brasileira, 2006. 
MACEDO, E. Base Nacional Curricular Comum: novas formas de sociabilidade produzindo sentidos para a educação. Revista e-Curriculum, São Paulo, v. 12, n. 03, out./dez. 2014.

MACEDO, E. Currículo: política, cultura e poder. Currículo sem Fronteiras. v.6, n.2, p.98-113, Jul/dez. 2006.

MACEDO, E. Mas a escola não tem que ensinar? Conhecimento, reconhecimento e alteridade na teoria do currículo. Currículo sem Fronteiras, v. 17, n. 3, p. 539-554, set./dez. 2017.

PARAísO, M. O Desempenho como Tecnologia de Governo de Estudantes no Currículo. In: Maria Zuleide Costa Pereira, Idelsuite de Sousa Lima. (Org.).

Currículos e Políticas Educacionais em debate. Campinas: Alínea, 2012, p. 87103.

PARAÍSO, M. Currículo-nômade: quando os devires fazem a diferença proliferar. In: COSTA, M. E. (Orgs.). Estudos Culturais e Educação:

contingências, articulações, aventuras, dispersões. Editora Ulbra. Canoas. 2015, p. 269-288.

PARAÍSO, M. Currículo e relações de gênero: entre o que se ensina e o que se pode aprender. Revista Linhas. Florianópolis, v. 17, n. 33, p. 206-237, jan./abr. 2016.

POOLI, J. A filosofia da educação e a maquinaria escolar: entre discursos e práticas. Anais. X ANPED SUL, Florianópolis, outubro de 2014.

VARELA, J; ALVAREZ-URIA, F. A Maquinaria Escolar. Teoria e educação. 6 , 1992.

Recebido em: 02 de fevereiro de 2019

Aprovado em: 26 de agosto de 2019 